\title{
Modelo de desarrollo y élites económicas en Bolivia: análisis de la concepción de desarrollo ancestral del presidente Evo Morales ${ }^{\star}$
}

\author{
Johanna Amaya** \\ Juan Federico Pino**
}

Recibido: 15 de marzo de 2015

Evaluado: 27 de abril de 2015

Aceptado: 7 de abril de 2015

\section{RESUMEN}

Actualmente el Estado Plurinacional de Bolivia atraviesa un conflicto determinado por la tensión entre dos concepciones de desarrollo: la del presidente Evo Morales —basada en la hibridación entre pensamiento ancestral con el socialismo- y la de la oposición, liderada por el Gobierno regional de Santa Cruz de la Sierra, fundada en la concepción capitalista transnacional de las élites tradicionales del país. Este proyecto analiza las relaciones existentes entre la concepción del desarrollo del presidente indígena, con su concepción socialista, y la incidencia de la capacidad productiva de las élites santacruceñas en la puesta en marcha del modelo nacional de Morales.

Palabras clave: modelo de desarrollo, élites, democracia, compañías transnacionales

Artículo de investigación realizado en la línea de Globalización, Internacionalización y Desarrollo del GIERSP "Grupo Interdisciplinar de Estudios sobre Religión, Sociedad y Política" de la Universidad de San Buenaventura.. Cómo citar este artículo: Pino, J. F. y Amaya, J. (2015). Modelo de desarrollo y élites económicas en Bolivia: análisis de la concepción de desarrollo ancestral del presidente Evo Morales. Hallazgos, 12(24), 241-255 (doi: http://dx.doi.org/10.15332/s1794-3841.2015.0024.13)..

** Politóloga e Internacionalista, Universidad Javeriana (Colombia); M.A. en Estudios Latinoamericanos. Profesora, directora de investigación, Universidad de San Buenaventura (Colombia). Correo electrónico: lamaya@javeriana.edu.co

*** Politólogo, Universidad Javeriana; M.A en Ciencia Política, Universidad de los Andes (Colombia) y candidato a doctor en Ciencia Política de la misma universidad. Profesor de la Universidad del Rosario (Colombia). Correo electrónico: jf.pino31@uniandes.edu.co 


\section{Development model and economic elites in Bolivia: analysis of the conception of ancestral development of President Evo Morales}

\begin{abstract}
Currently the Plurinational State of Bolivia faces a conflict determined by the tension between two antagonistic conceptions of economic development: President Evo Morales's conception based in the mixture of the ancestral indigenous conception of the world on the one hand and the socialist economic model on the other, and the capitalist conception led by the regional government of Santa Cruz de la Sierra, supported by the transnational companies and the country's traditional elites. This article analyzes the relationship between the concept of development of the indigenous president and the socialist model, and the incidence of the elites of Santa Cruz de la Sierra in the implementation of President's Morales model taking into account the control they have of the productive apparatus.
\end{abstract}

Keywords: Development model, elites, democracy, transnational companies.
Received: March 15, 2015

Evaluated: April 27, 2015

Accepted: April 7, 2015 


\section{Modelo de desenvolvimento e elites econômicas na Bolívia: análise da concepção de desenvolvimento ancestral do presidente Evo Morales}

Recebido: 15 de março de 2015

Avaliado: 27 de abril de 2015 Aceito: 7 de abril de 2015

\section{Resumo}

$\mathrm{Na}$ atualidade o Estado Plurinacional da Bolívia atravessa um conflito determinado pela tensão entre duas concepções de desenvolvimento: uma do presidente Evo Morales - baseada na hibridação entre o pensamento ancestral com o socialismo - e outra da oposição, liderada pelo governo regional de Santa Cruz de la Sierra, fundamentada na concepção capitalista transnacional das elites tradicionais do país. Este projeto faz uma análise das relações existentes entre a concepção do desenvolvimento do presidente indígena, com sua concepção socialista e a incidência da capacidade produtiva das elites de Santa Cruz de la Sierra na execução do modelo nacional de Morales.

Palavras-chave: modelo de desenvolvimento, elites, democracia, companhias transnacionais. 


\section{INTRODUCCIÓN}

Actualmente, América Latina vive profundos conflictos sociales que se expresan en una suerte de "guerra de territorios", donde actores sociales antagónicos intentan controlar espacios territoriales como una manera de imponerle a sus adversarios relaciones de poder favorables a sus intereses (Zibechi, 2009, p. 317).

Estos conflictos están determinados por la pugna entre dos visiones del mundo que coexisten en nuestro territorio latinoamericano: desarrollo capitalista y desarrollo autónomo tradicional; de acuerdo con usos y costumbres de los pueblos originarios o tradicionales. Uno de los casos más sobresalientes de esta disputa se da en Bolivia, donde el conflicto político, económico, social y territorial del Gobierno del presidente indígena Evo Morales Ayma con las élites de Santa Cruz de la Sierra es evidente en torno a la visión de desarrollo económico del país.

Bolivia es un país rico en recursos mineros y energéticos. Su economía ha dependido principalmente del sector primario, con la extracción y exportación de materias primas, aunque la industria y el sector de servicios es importante en algunos departamentos. Históricamente el Estado y el poder político han sido controlados por terratenientes mestizos o blancos pertenecientes a élites regionales (Peña, 2003; Assies, 2009). Lo anterior se traduce en una alta concentración del ingreso: un índice Gini de 56,3 para el 2008; el sexto puesto en el índice Gini por país a nivel mundial (Banco Mundial, 2013).

La concentración de la riqueza contrasta con el hecho de que - pese a tratarse de un Estado plurinacional con una amplia presencia de población indígena: 62,2\% (Centro Latinoamericano y Caribeño de Demografía 2013) - la mayoría de indígenas viven en condiciones precarias e incluso de esclavitud. La inconformidad de una población mayoritaria en términos cuantitativos y minoritaria en términos políticos y económicos se reflejó en la Guerra del gas y la consecuente renuncia del presidente Mesa. En ese entonces, los bloqueos generados por el movimiento cocalero liderado por Evo Morales estaban dirigidos a presionar al legislativo para aprobar la Ley de Hidrocarburos, destinada a aumentar las regalías del $18 \%$ al $50 \%$ y a reclamar la propiedad estatal absoluta sobre los hidrocarburos y el gas, así como la convocatoria a una Asamblea Nacional Constituyente.

El interés en las regalías se puede explicar por el hecho de que el modelo de desarrollo del presidente Morales presenta un híbrido entre la concepción del pensamiento ancestral indígena y el socialismo; dicha mezcla podría explicar-hipotéticamente- el acentuado interés de este Gobierno por las regalías (Cunha, Mendonça y Gonçalves, 2010). Pues si bien favorece la explotación de un recurso "sagrado", que en una concepción puramente indígena se protegería, se podría afirmar que dichas acciones están dirigidas a consolidar un capitalismo de Estado (como fase del socialismo).Se busca nacionalizar recursos con el fin de quitarlos de manos de privados y multinacionales, para redistribuirlos entre los nacionales más pobres (Sandoval, 2010, p. 1). La cuestión de la regulación de las regalías por parte del Estado sigue siendo un asunto central hasta la actualidad en la puesta en marcha del modelo de desarrollo de este Gobierno. 
La hibridación en el discurso y puesta en práctica de un modelo indígena-socialista de Morales obedece a una mixtura entre un concepto típicamente occidental como lo es el desarrollo, articulado a la definición de un Estado plurinacional, que le apuesta al desarrollo de las autonomías locales de acuerdo con usos y costumbres tradicionales de los pueblos, en medio de un sistema económico capitalista y de un Estado en el que las mayorías indígenas se han visto históricamente excluidas (Assies, 2009).

En suma, el modelo de desarrollo planteado por Morales intenta articular su cosmovisión del pensamiento ancestral indígena con una plataforma de corte socialista que se traduce en su Plan de Desarrollo Nacional: Bolivia digna, soberana, productiva y democrática para Vivir Bien¹. La inserción de un modelo de corte popular y socialista ha desencadenado conflictos internos entre el Gobierno y la oposición de sectores productivos y terratenientes tradicionales de élite, principalmente en el departamento de Santa Cruz, la región más rica y más poblada de todo el país, la cual se ha preocupado por garantizar su autonomía regional con el fin de ejercer su actividad económica capitalista, en franca y abierta oposición a la apuesta nacional del reelecto presidente Morales (Quiroga, 2014).

Como indicador del nivel de polarización del conflicto expuesto, se puede observar cómo, pese al éxito electoral de Morales: $54 \%$ de los votos en primera vuelta durante su primer Gobierno, ratificado con un $67,43 \%$ a favor en referendo revocatorio de 2008 y reelegido con $62 \%$ de los votos en

1 República de Bolivia. Plan Ministerio de Planificación del Desarrollo Nacional de Desarrollo: Bolivia digna, soberana, productiva y democrática para Vivir Bien 2006-2010. primera vuelta, la oposición goza de gran legitimidad a nivel regional: el prefecto de la oposición de Santa Cruz, Rubén Costas, fue ratificado en dicho referendo con $66 \%$ de los votos a favor y reelegido en 2010 con $54 \%$ de votos (Whitehead, 2001).

Esta situación denota la conformación de dos bandos rivales y polarizados en lo que a la estructura de la propiedad y de la riqueza del país atañe. Esta puja electoral es solo el reflejo de la pugna entre movimientos sociales que privilegian la politización de la identidad indígena-originaria y el proyecto conservador encarnado en el seno del proceso constituyente boliviano (Vacaflores, 2009. p. 333), se trata de una condición de colonialidad o poscolonialidad en la que se continúan privilegiando las epistemologías y las prácticas referidas al ser, al saber y al poder (Walsh, s. f., p. 1) propias del modelo homogenizante de mercado (Schavelzon, 2012).

Así es como - teniendo en cuenta las variables descritas - la pregunta que motiva este proyecto de investigación es ¿cuál es la incidencia de la capacidad productiva de las élites santacruceñas en la puesta en marcha del concepto de desarrollo del pensamiento indígena-socialista de Evo Morales?

A modo de hipótesis se sostiene que ante la presencia de dos proyectos opuestos de desarrollo económico, político y social se debe producir una convergencia política a través la construcción de consensos que eviten que el crecimiento económico y desarrollo social alcanzado se desaceleren, y que los efectos redistributivos no lleguen a las poblaciones más pobres y vulnerables, pues esta situación conduciría a la frustración de ambos proyectos (Sandoval, p. 2010, p. 6); de lo contrario, la capacidad política y económica 
de la oposición terminará por jaquear la implementación de la apuesta de Morales.

En este sentido, el objetivo general de esta investigación es analizar la concepción de desarrollo ancestral en un modelo de desarrollo indígena y socialista planteado por el presidente Evo Morales Ayma, en relación con la incidencia de la capacidad económica y terrateniente de la población de Santa Cruz y su vinculación a dicho modelo de desarrollo. Como objetivos específicos se proponen los siguientes:

1. Analizar la manera como se hibridan los principios del pensamiento ancestral indígena con los del socialismo en la propuesta de desarrollo planteada por el Gobierno del presidente Evo Morales Ayma y la forma como plantean una concepción de desarrollo alternativa al modelo oligárquico.

2. Analizar los objetos centrales o fundamentos de la disputa entre la concepción de desarrollo del Gobierno nacional boliviano y la oposición del Gobierno local del departamento de Santa Cruz de la Sierra.

3. Definir los alcances de la propuesta de desarrollo planteada por el presidente Evo Morales en relación con la capacidad productiva y la propuesta de la oposición santacruceña.

\section{Análisis del modelo de DESARROLLO DEL PRESIDENTE Evo Morales Ayma: conflicto EN LAS CONCEPCIONES DE desarrollo del Gobierno y DE LA OPOSICIÓN}

Los modelos de desarrollo implementados en la historia de Bolivia han traído como consecuencia la conformación de una economía con serias deficiencias estructurales que perpetúan un esquema inequitativo, basado en la concentración de la tierra y de la riqueza, que mantiene y profundiza una pobreza estructural:

"La relación de la economía boliviana y su vinculación con los centros de poder que ha originado la explotación sucesiva de la plata, la goma elástica, el estaño, el petróleo y actualmente, el gas, sin vinculación con el conjunto de los otros sectores productivos, concentrando la riqueza en unos sectores, mientras que la mayoría de la población vive bajo la pobreza. El PNUD ha caracterizado este problema estructural como el patrón de acumulación de "base estrecha". A través de la historia de Bolivia, se van modificando modelos económicos, pero sin que se logre salir de este "patrón de acumulación [...] la pobreza es un problema estructural, que proviene tanto de la muy mala distribución del ingreso, como de la relación de la economía boliviana con el resto del mundo a través de la explotación de recursos naturales. Es decir, la estructura económica combina sectores muy productivos y con alta inversión tecnológica, pero que emplean a pocos trabajadores versus sectores poco productivos, con insuficiente capital, pero intensivos en fuerza de trabajo" (Sandoval, 2010, p. 1).

Así pues, como sostiene Sandoval, la limitación de fondo es la ineficiente distribución del ingreso: el $10 \%$ de la población concentra el $46 \%$ del ingreso (Fundación Jubileo, 2005), que sitúa a Bolivia como una de las economías más inequitativas de Sudamérica. Esta situación es consecuencia de los efectos adversos de la implementación del 
modelo neoliberal, que parte del falso supuesto según el cual los esfuerzos debían concentrarse en la acumulación de capitales, por cuanto que esta se vería reflejada automáticamente en la redistribución de las ganancias; según este esquema la acumulación en la punta de la pirámide produciría en efecto de "goteo" hacia abajo, aspecto que garantizaría que la base de la pirámide se beneficiaría de la acumulación generada arriba. Así es como:

Los principales factores estructurales inciden en la inequidad son la educación, la distribución inequitativa de la tierra y el desarrollo basado en Recursos Naturales. El crecimiento y la distribución constituyen dos factores principales que determinan mancomunadamente la pobreza en términos de ingresos de los hogares. La desigualdad de ingresos influye en gran manera en el nivel de pobreza de un país, reduciendo o incluso eliminando el efecto que tiene el crecimiento sobre la pobreza (Sandoval, 2010, p. 2).

Este efecto fue producido por la implementación del modelo neoliberal y condujo a una situación económica deficitaria que alcanzó en niveles del $11 \%$ a principios del siglo XXI, todo ello como consecuencia de la recesión económica mundial a finales del siglo XX, la cual es producto de la crisis de la implementación de dicho modelo.

Ante este panorama general, el modelo de desarrollo del Movimiento al Socialismo-y específicamente del presidente Evo Morales - formula una política de capitalismo de Estado, de manera que busca recuperar el control sobre los sectores estratégicos de la economía, los cuales fueron supeditados a la dinámica del mercado bajo la lógica neoliberal (Cunha, Mendonça y Gonçalves, 2010; Schavelzon, 2012). Al mismo tiempo, se acentúa el factor de la producción comunitaria tradicional, situación que se refleja en el objetivo del Plan del Desarrollo Nacional: "Constituir un Estado con potencia transformadora que reconozca los diversos actores sociales y de las economías, estatal, privada, comunitaria y mixta". El principal lineamiento del Plan Nacional de Desarrollo se refiere a la transferencia de excedentes entre los sectores generadores de excedentes y los generadores de ingresos y empleo (Sandoval, 2010).

Esta apuesta es una muestra de la hibridación entre supuestos socialistas y la concepción tradicional de la producción indígena y campesina. Es importante anotar que el desarrollo, al ser un discurso de Occidente (Escobar, 2005), es reciente respecto a la concepción de desarrollo las comunidades originarias. Este es un discurso homogenizante e impuesto desde la episteme occidental, o la colonialidad del ser, del saber y del poder, como la ha denominado el grupo modernidad-colonialidad, de los estudios poscoloniales latinoamericanos, que deja de lado las concepciones y prácticas tradicionales de autodeterminación e impone un esquema uniformador, que legitima al referente occidental como patrón único de progreso y modernización.

En el caso de Bolivia, se puede observar cómo-a la manera de una estrategia de supervivencia- el pensamiento ancestral se "camufla" e hibrida en el discurso del desarrollo alternativo al circunscribirse en una etiqueta socialista; muestra de ello es que el vicepresidente de Bolivia sea un ícono intelectual y político del socialismo boliviano. 
La pugna sobre el modelo de desarrollo que debe predominar en Bolivia se inscribe dentro de esta paradoja de la modernidad: autonomías vs. homogenización occidental. El punto central de la discusión es hacia dónde se camina: ¿hacia el referente modernizante impuesto por la globalización (que se erige como única opción e inevitable) o hacia la consolidación de la concepción propia de desarrollo a partir de usos y costumbres tradicionales en alianza coyuntural con el socialismo? Las élites de Santa Cruz le apuestan al primer camino, y Morales, al segundo.

Sin duda, la reproducción del modelo modernizante obedece a la continuidad de la colonia -entendida como estructura de conocimiento y de poder- a la manera de poscolonialidad (Castro-Gómez, 2005). La resistencia indígena adopta formas del discurso moderno bajo la etiqueta socialista; sin embargo, es posible afirmar que se trata de la única posibilidad de crear alternativas de desarrollo propio, ante la dinámica avasalladora del capital transnacional y del modelo del agro-negocio en América Latina.

El discurso del desarrollo se erige — desde esta perspectiva- en la reacomodación de las prácticas coloniales que hoy reconocen formalmente el valor de los conocimientos tradicionales en el manejo de los recursos naturales, y en la realidad los utilizan para expandir la dinámica de explotación transnacional, que ahora adopta formas más sutiles, aunque continúa implementando el recurso de la violencia, lo cual se hace evidente en la alianza estratégica entre empresarios transnacionales y militares.
En este sentido, el conflicto por la autonomía del departamento de Santa Cruz con el presidente Morales tiene sus raíces en la estructura de la propiedad de la tierra, pues buena parte del poder de la oligarquía boliviana que funge como oposición se asienta en este recurso, el cual fue adquirido de manera fraudulenta durante las dictaduras militares. El agro-negocio es la principal fuente de acumulación de las élites locales, vinculadas al parecer a negocios ilícitos como el narcotráfico y el contrabando, y ubicadas junto a Tarija en la región más rica en hidrocarburos. Santa Cruz es la región más conservadora, de la que partieron golpes de Estado decisivos como el de 1971 (Peña, 2003). Una manera de evitar que el proceso de acumulación de las élites tradicionales de Santa Cruz se vea afectado es defender un proyecto autonómico, que ha producido un alto nivel de polarización y que podría desatar una guerra interna, de carácter separatista encabezada por la oligarquía cruceña y apoyada por las élites políticas de los departamentos de la media luna: Pandi, Beni y Tarija, en la que se produciría un conflicto entre Oriente y Occidente que redundaría en la fractura del país entre el altiplano indígena y los departamentos en mención (Zibechi, 2009, p. 318).

Santa Cruz se ha caracterizado históricamente por su tradición separatista y de derecha. Desde 1950, estuvo vinculado a la Falange Socialista Boliviana desde la revolución de 1952, momento en el que reclamaba el $11 \%$ de las regalías. En julio de 1959, durante el gobierno de esta falange, el Gobierno de la Paz debió recuperar el control sobre el departamento mediante las fuerzas armadas (Peña, 2003). Hacia 1970 Santa Cruz ya era la zona más rica del país, lo que 
le permitió destacarse en la política nacional. Actualmente sus élites se han transnacionalizado: los terratenientes se han transformado en empresarios multinacionales. A partir de su fuerza económica y política, las élites de Santa Cruz pasaron de demandar descentralización a exigir autonomía, capacidad de autogobernarse y, a partir de allí, extender su hegemonía al conjunto del país (Sivak, 20007, p. 43).

La agudización del conflicto, como lo sostiene Zibechi, se denota en la presencia de campos de entrenamiento de grupos de paramilitares con presencia de mercenarios colombianos en Santa Cruz, lo cual demuestra que la apuesta por la guerra de las clases dominantes se dirige a garantizar el control territorial adquirido por ellas. Este sector ha logrado movilizar a cientos de bolivianos a favor de la autonomía como horizonte de prosperidad, lo que ha incitado a los odios raciales y el desprecio entre indios y mestizos (cambas y collas).

En contrapeso al poder de las élites ganaderas y agrícolas del país, el presidente indígena busca fortalecer los sectores aborígenes y populares entregándoles tierras, pese al saboteo de dichas élites, que han recurrido a la amenaza para obstaculizar este proceso, pues la precaria condición de vida de las poblaciones originarias favorece tano su estructura productiva, como de la propiedad:

En el Alto Parapetí, en la provincia Cordillera del departamento de Santa Cruz, viven tres mil familias guaraníes, de diecinueve comunidades en condiciones de servidumbre en haciendas feudales. Las tierras de las comunidades fueron usurpadas por los hacendados y ahora los indígenas trabajan para sus amos sin recibir salario, salud y educación, y deben pagar por las cosechas que siembran [...] viven cautivos en situación de esclavitud (Zibechi, 2009, p. 319).

La condición de esclavitud de los indígenas bolivianos ha sido ratificada por la Organización de Estados Americanos (OEA), la Organización Internacional del Trabajo (OIT) y el Programa de las Naciones Unidas para el desarrollo (PNUD) (2005), y ante los intentos de reforma y saneamiento de las tierras por parte del Gobierno de Morales, los terratenientes han reaccionado con levantamientos violentos y agresiones a los funcionarios, con el fin de evitar la legalización de títulos de propiedad y la verificación de las condiciones de sus trabajadores.

Este es un ejemplo de la manera como se configuran territorialidades excluyentes derivadas de monocultivos de commodities que conforman "campos de fuerza" capaces de jaquear al sistema democrático. La ofensiva de los grandes propietarios produce la organización de la resistencia indígena y campesina, las áreas rurales conquistadas por monocultivos en toda América Latina ( $\mathrm{Zi}$ bechi, 2009, p. 322). Al parecer de Zibechi, este es un fenómeno que se está dando en todo el continente con diversas características, ritmos y modos; ejemplo de ello son los conflictos entre el sector campesino y el Gobierno de Cristina Fernández en Argentina, la expansión del agro-negocio y el monocultivo en Brasil y Colombia, la creación de grupos paramilitares legales en Paraguay, que reprimen a aquellos movimientos que se oponen a la expansión del monocultivo, y la expansión de monocultivos forestales en Chile. 
Se trata principalmente de un maridaje que legitimó el modelo neoliberal del desarrollo: capital financiero y grandes empresas transnacionales aliadas para dominar la agricultura en todo el continente, ello con el patrocinio de los Gobiernos locales que favorecen mediante sus políticas la expansión del agro-negocio. Este modelo se caracteriza por favorecer la concentración y centralización de la tierra, el control de las cadenas productivas, del mercado interno y externo, de los precios y los insumos, todo lo cual provocó que cada cadena productiva quedara tan solo en manos de tres o cuatro grandes empresas, en el caso de Bolivia, aliadas a la oposición. Este modelo no deja espacio para la agricultura familiar y mucho menos para la consolidación de un mercado interno o la implementación de una reforma agraria (Zibechi, 2009, p. 325).

La dinámica expuesta ha llevado al desplazamiento dirigido a partir de medidas gubernamentales; este pretende forzar la migración del campo a las ciudades, bien sea a través de las armas y la guerra - por vía legal o ilegal- o como consecuencia de la dinámica del libre mercado. Siguiendo a Zibechise puede observarse la manera como relaciones de poder se reconfiguran con el monocultivo, pues a partir de esta lógica son desplazados y destruidos aquellos lugares donde se desarrollaba una producción tradicional-artesanal en las áreas rurales y se impone el modelo del agro-negocio.

En este sentido, se impuso lo que Porto Gonçalves (2007) denomina como el "complejo técnico-militar-empresarial" que se erige en una especie de panóptico (Foucault, p. 1976) biopolítico (Foucault, 1992), que termina por adoptar formas "monstruosas" antinaturales, determinadas por los "avances" de la manipulación genética y la uniformización de la diversidad ecológica, en sistemas regularizados y homogéneos de producción, típicos del monocultivo. En términos políticos, se trata de una estructura vertical y autoritaria que busca manipular las formas de vida en función de la cualificación de la estructura productiva y de poder del agro-negocio.

En palabras de Zibechi, se trata de reconfiguración completa de las formas de dominación, de establecer un nuevo panóptico rural y urbano: en el campo, gigantescas áreas homogenizadas vigiladas por guardias empresariales; en las ciudades, en las periferias se hacinan los desplazados de la guerra por los territorios; los Estados atienden a los nuevos pobres — sin tierra, sin techo y sin derechos- mediante planes sociales focalizados diseñados por el Banco Mundial. Se trata de un sistema que condiciona cualquier política, de un modelo que trae una guerra contra la población, el vaciamiento del campo, la eliminación de la memoria del pueblo para hacinarlo en las ciudades y convertirlo en fiel consumidor de lo que el mercado le depare (Rulli, 2007, p. 7). Esta dinámica funciona en Bolivia y tiene por objeto detener cualquier cambio en la acumulación por parte de transnacionales y élites locales.

La alternativa planteada por el MAS y el Presidente Morales a nivel económico consiste en concentrarse en la propiedad del Estado sobre los sectores estratégicos ya que, según lo define su Plan de Desarrollo Nacional "La estructura de la matriz productiva nacional se basa en Sectores estratégicos generadores de excedentes: Hidrocarburos, 
minería, electricidad, Recursos ambientales que deberían transferir excedentes a los sectores generadores de ingresos y empleo (agropecuaria, manufactura, turismo, vivienda)" (Ministerio de Planificación del Desarrollo, 2007). Por lo tanto, propone en este mismo plan una "Política de tratamiento a la inversión extranjera que otorgue seguridad jurídica y reglas claras sobre su aporte al Estado, pero a la vez presencia efectiva del Estado en el ciclo productivo" (2007).

La intervención del actual Gobierno ha redundado en el aumento de los índices del crecimiento económico que se reflejan en al aumento del producto interno bruto (PIB) del $4,2 \%$ en 2006 al $6 \%$ en 2008, con promedio del 5,1\% anual, mientras que durante la crisis de 2003-2006 alcanzó niveles de tan solo 2,5\%. Así mismo, el PIB per cápita aumentó de mil dólares en 2006 a mil trescientos en 2007, y aunque la cifra es favorable, no resulta tan significativa por la mala distribución del ingreso. Por otra parte, ya desde 2004 se observa una tendencia al aumento de las exportaciones. Se consideraba un gran logro haber superado los $2000 \mathrm{mi}-$ llones de dólares en exportaciones; el 2007, las exportaciones llegaron a la histórica cifra de 4793 millones de dólares, y de enero a junio de 2008 llegaron a 2588 millones de dólares, lo que hace suponer que hasta fin de año podrían acercarse o superar los 5000 millones de dólares. Desde 2004, hay superávit comercial, las importaciones también han ido creciendo; esta situación es más favorable en las tres últimas gestiones (Sandoval, 2010, p. 3).
Sandoval demuestra que dentro de los efectos positivos del modelo de desarrollo del actual Gobierno de Bolivia se destaca que:

La Inversión Pública llegará este año a un récord de 1300USD millones. Además, se ha creado un Banco de Desarrollo Productivo (BDP), para apoyar emprendimientos privados. La deuda pública externa, bajó de 5.142 millones de dólares, el año 2003, a 2.242 millones de $\$$ us, a junio de 2008, debido a las negociaciones que lograron la condonación de la deuda externa. Los ingresos tributarios han aumentado, tanto por el incremento del número de contribuyentes, (de 22.018 el 2005 a 275.264, el 2007), como por los montos recaudados. De 15.085 millones de Bs., se subió a 23.229 millones de Bs. el año 2007. Los ingresos por aduanas entre $2000 \mathrm{y}$ 2004, se acercaban a los 3.000 millones de Bs. A 2007, se ha alcanzado los 4.956 millones de Bs. Estos incrementos pueden explicarse en una mejor gestión y confianza en la administración actual y en una mayor rigidez en la aplicación de normas tributarias. La aplicación de la Nueva Ley de Hidrocarburos genera ingresos notables, 1.845 millones de \$us el 2006, 1976 millones de \$us, el 2007 y se estiman 2.627 el 2008. Entre 2001 y 2003, los ingresos por hidrocarburos, estaban en promedio en 472 millones de \$us anuales. Estos nuevos ingresos han creado excedentes para la distribución., Así, el 2005, las prefecturas, municipios y universidades recibieron 1218 millones de Bs., el 2006, 3520 millones de Bs y el 2007, 3.904 millones de Bs. La reactivación de la minería a partir de los mejores precios 
internacionales [...] El saneamiento de tierras, avanza con mayor celeridad y eficiencia. En 10 años se titularon 9,3 millones de hectáreas con una inversión de más de 85 millones de dólares, en la gestión actual se tituló 14,79 millones de has, con un costo de 17 millones de dólares.

Según los datos reseñados, la intervención de Morales ha resultado favorable para el país y ha conseguido salir de la crisis a la que condujo el modelo neoliberal, por medio de la puesta en marcha de una política económica dirigida desde el Estado. Sin embargo, pese a estos efectos positivos, el modelo del actual presidente enfrenta algunas amenazas, por cuanto presenta la segunda inflación más alta de América Latina según la Comisión Económica para América Latina y el Caribe (Cepal) (2008), lo cual afecta negativamente la capacidad adquisitiva de las familias y redunda en la disminución en la capacidad de los pobres en el acceso a los alimentos. En segundo lugar, la percepción de inestabilidad política y las leyes que condicionan a empresas extranjeras a aportar un porcentaje significativo para el país, ha disminuido notablemente la inversión extranjera directa, y dada la revaluación de la moneda, ha afectado negativamente a los exportadores. En tercer lugar, el desempleo, aunque disminuyó (Instituto Nacional de Estadística de Bolivia, 2005), continúa siendo un problema estructural, asociado al subempleo (Sandoval, 2010, pp. 6, 7).

Al parecer de Sandoval (2010), al realizar un balance de los impactos positivos y los negativos para Morales se definen oportunidades como cumplir con lo planificado en el Plan Nacional de Desarrollo, por la situación de auge de ingresos de la economía boliviana, que le da la posibilidad de transferir recursos de los sectores generadores de ingresos como los hidrocarburos a los pequeños productores generadores de empleo; renegociar los precios de hidrocarburos y minerales con los vecinos para obtener mayores ingresos, debido al alto nivel que estos han alcanzado; incrementar la inversión privada y extranjera a partir de la consolidación de una mayor estabilidad política.

\section{Conclusión}

A modo de conclusión, es posible afirmar que una vez implementado el modelo de desarrollo del MAS y del presidente Morales, dado los resultados positivos que ha generado en términos económicos y sociales a partir del control de los sectores estratégicos por parte del Estado, no parece adecuado retornar a la implementación de un modelo neoliberal radical como el que fue aplicado en los Gobiernos que precedieron a Morales. Sin embargo, aunque los ingresos en el nivel nacional han crecido significativamente, aún en medio conflicto regional del Gobierno socialista con el Gobierno regional de Santa Cruz de la Sierra, se hace necesario adoptar medidas que logren conciliar y equilibrar los intereses regionales con los nacionales que redunden en medidas redistributivas que favorezcan a la mayoría de la población boliviana.

La polarización de este conflicto ideológico, político y económico tiene altas posibilidad de desencadenar en una guerra interna por el control del territorio y la radicalización de quienes abanderan ambos modelos de desarrollo. Esto llevaría al traste los logros alcanzados hasta ahora por el Gobierno de 
Morales, por cuento produciría efectos negativos sobre el crecimiento económico e imposibilitaría que las políticas redistributivas llegaran a las poblaciones vulnerables (Sandoval, p. 2010). Es necesario transitar hacia acuerdos políticos dirigidos a evitar estos efectos; de lo contrario la violencia se hace inminente.

A nivel económico, se deben tomar medidas dirigidas a palear el efecto inflacionario, a incentivar la producción y la inversión, de modo que se haga posible efectuar las medidas de redistribución de manera sostenible.

Finalmente, respecto de la recurrencia del fenómeno del agro-negocio en la región latinoamericana, y los conflictos territoriales derivados del mismo, se denota la estructura de un modelo global que arrasa con las concepciones tradicionales $\mathrm{y}$ aborígenes de vida y de autonomía cultural, política, social y económica. Si bien el proyecto del presidente Evo no representa una postura radica lo purista respecto a la defensa del pensamiento indígena, sino más bien una mixtura con el discurso y práctica occidental de socialismo, su Gobierno ha traído avances significativos en la protección de esas formas y culturas tradicionales. Estas se ven hoy avasalladas por el modelo que imponen empresas transnacionales en alianza con técnicos y militares en diferentes zonas del continente latinoamericano, que se ven azotadas por la violencia y la devastación de sus territorios; dinámica que ha operado - de maneras diferentes y con diversos ritmos y estrategias- desde la Colonia hasta nuestros días. La Colonia -entendida no solamente como período histórico, sino como estructura de pensamiento, de conocimiento de organización y de producción (Castro-Gómez, 2005) - continúa y se reproduce en estos conflictos. Muestra inminente de lo anterior es la persistencia la esclavitud en el país en las zonas de la "media luna": Pandi, Beni y Tarija, fenómeno ante el cual deben tomarse medidas inmediatas que lleven a su abolición, no solo por parte del Estado boliviano, sino también por parte de la comunidad internacional que reconoce su existencia.

La posibilidad de construir nociones acordadas y sostenibles de desarrollo en este país está determinada por la capacidad de producir diálogos de saberes interculturales en torno a la construcción de una noción compartida de futuro. Sin embargo, en tanto que esto no se haga realidad, la posibilidad de plasmar y sostener la propuesta de desarrollo del presidente indígena se verá jaqueada por la inminente capacidad productiva de las élites santacruceñas y el impulso del modelo del agro-negocio por parte de las empresas transnacionales en toda la región latinoamericana. La posibilidad de llevar a cabo este modelo de desarrollo alternativo está marcada por la eventualidad de realizar acuerdos con las élites cruceñas y por la capacidad de llevar a cabo y fortalecer acuerdos internacionales, inicialmente a nivel regional y luego a nivel internacional, en el marco, por ejemplo, de la Comunidad Andina (CAN), Asociación Latinoamericana de Integración (ALADI) y el Sistema Global de Preferencias Comerciales (SGPC) entre los países en desarrollo, que lleven a la creación de alianzas que hagan posible y sustentable esta apuesta a partir de una estrategia de integración regional. 


\section{REFERENCIAS}

Assies, W. (2009). La "media luna" sobre Bolivia: nación, región y clase social. América Latina Hoy, 43. Recuperado el 14 de septiembre de 2014, de http://revistas.usal.es/ revistas_trabajo/index. php/1130-2887/article/view/2473

Banco Mundial (2013). Índice de Gini. Recuperado el 1 de octubre de 2014, de<http://www.http://datos.bancomundial. org/indicador/SI.POV.GINI

Castro-Gómez, S. (2005). La poscolonialidad explicada a los niños. Bogotá: Pensar.

Centro Latinoamericano y Caribeño de Demografía (Celade) (2013). Informe de actividades del Centro Latinoamericano y $\mathrm{Ca}$ ribeño de demografía División de Población de la CEPAL. Fondo indígena. Recuperado de http://www.cepal.org/celade/ noticias/documentosdetrabajo/4/50564/ CRPD_LCL3643_Esp.pdf

Christensen, S. F. (2006). La política energética de Bolivia y las relaciones entre Bolivia y Brasil. Sociedad y Discurso, (10), 1-24.

Corte Nacional Electoral Bolivia (s. f.). Recuperado el 14 de septiembre de 2014, dehttp://www.oep.org.bo/

Cunha Filho, C. M. y Santaella Gonçalves, R. (2010) The National Development Plan as a Political Economic Strategy in Evo Morales's Bolivia. Accomplishments and Limitations. Latin American Perspectives, 37(4), 177-196.

De Sousa Santos, B. (2007). La reinvención del Estado y el Estado plurinacional. Alianza Interinstitucional. Centro de Estudios Nacional de Desarrollo Alternativo -Centro de Estudios Jurídicos e Investigación Social, Centro de Documentación e Información Bolivia. Recuperado el 8 de octubre de 2014, de http://www.bivica. org/upload/Estado- reinvencion.pdf

Escobar, A. (2005). Más allá del tercer mundo: globalización y diferencia. Bogotá: Instituto Colombiano de antropología e Historia [Icanh].

Foucault, M. (1992). Genealogía del racismo. De la guerra de las razas al racismo de Estado. Madrid: La Piqueta

Foucault, M. (2005). Vigilar y castigar. El nacimiento de la prisión. México, D. F.: Siglo XXI.

Fundación Jubileo. (2005). La brecha entre ricos y pobres se ensancha. Informe. La Paz

Gray Molina, G. (mayo-junio, 2007). El reto posneoliberal de Bolivia. Nueva Sociedad, (209), 118-129.

Matus, M (2004). Obstáculos y promesas del desarrollo en Bolivia: claves históricas y territoriales. En J. Prats (Ed.), Bolivia: el desarrollo posible, las instituciones necesarias (pp. 63-148). Barcelona: Instituto Internacional de Gobernabilidad de Cataluña [IIG], Programa de Naciones Unidas para el desarrollo [PNUD].

Peña, P. (2003). La permanente construcción de lo cruceño: un estudio sobre la identidad en Santa Cruz de la Sierra. La Paz: Programa de Investigación Estratégica de Bolivia [PIEB].

Porto Gonçalves, C. (2007). Geo-grafías. Movimientos sociales, nuevas territorialidades y sustentabilidad. México, D. F.: Siglo XXI.

Prefectura del Departamento de Santa Cruz (2010). Plan Departamental de Desarrollo Económico y Social De Santa Cruz 2000. Recuperado de http://www.santacruz. gob.bo/archivos/PN04082010121505.pdf

Programa de las Naciones Unidas para el Desarrollo (2005). La economía más allá del gas. La Paz. 
Quiroga, M. (2014). Movilización social en Bolivia. La consolidación de lo indio como capital político. Conflicto Social, 2(1), 195-217.

República de Bolivia y Ministerio de Planificación del Desarrollo. Plan Nacional de Desarrollo: Bolivia digna, soberana, productiva y democrática para Vivir Bien. La Paz. Recuperado de http://www. ine.gob.bo/indicadoresddhh/archivos/ Plan\%20Nacional\%20de\%20Desarro1lo.pdf

Sandoval, C. D. (2010). Evaluación del modelo económico y gestión del gobierno del Presidente Evo Morales Ayma. Fundación Jubileo. Recuperado de http:// www.jubileoperu.org.pe/home/public_ html/jubileoperu.org.pe/wp-content/ uploads/2009/06/evaluacion_economica-bolivia.pdf

Schavelzon, S. (2012). El nacimiento del Estado plurinacional de Bolivia: etnografía de una asamblea constituyente. La Paz: Consejo latinoamericano de Ciencias Sociales [Clacso], Plural, Centro de Estudios Jurídicos e Investigación Social, Grupo Internacional de Trabajo sobre Asuntos Indígenas.

Sivack, M. (2007). Santa Cruz: una tesis. El conflicto regional en Boliva (2003-2006). La Paz: Plural.

Miguel Urioste F. de C. (2004). Bolivia: de la recuperación democrática de 1982 a la agonía de los partidos del 2004. En Grupo Propuesta Ciudadana (Ed.), La participación ciudadana y la construcción de la democracia en América Latina (pp. 99-117). Lima: Tarea Gráfica Educativa
Ministerio De Planificación del Desarrollo. (noviembre, 2007). Plan Nacional de desarrollo. Lineamientos Estratégicos 2006-2011. Recuperado de https:// www.google.com/url?sa=t\&rct=j\&$\mathrm{q}=\&$ esrc $=$ s\&source=web\&cd $=1 \& \mathrm{cad}=\mathrm{r}$ ja\&uact $=8 \&$ ved $=0$ CB0QFjAA\&url=http $\% 3 \mathrm{~A} \% 2 \mathrm{~F} \% 2 \mathrm{Fspin}$-be.unesco.org.uy $\%$ 2Fsubida\%2FdocrelArchivos\%2FPlan_ nacional_de_desarrollo.doc\&ei=0eGB VaTiKo7_gwTkqbK4BA\&usg=AFQjC NG_xGTfSyxdqMIWweEnYRCUrlJKh Q\&sig2=151GInZ8IirQ93fW1JYKQQ

Vacaflores, C. et al. (2009). La politización del territorio campesino. La lucha campesina por el reconocimiento en el proceso constituyente boliviano. En F. Lozano y J. Ferrro, J. (Ed.), Las configuraciones de los territorios rurales en el siglo XXI (pp. 333-351). Bogotá. Editorial Javeriana.

Walsh, C. (s. f.). Indisciplinar las ciencias sociales. Geopolíticas del conocimiento y colonialidad del poder. Perspectivas desde lo Andino. Quito: Universidad Andina Simón Bolívar /AbyaYala.

Whitehead, L. (2001). The emergence of democracy in Bolivia. En J. Crabtree y L. Whitehead (Eds.), In towards democratic viability: the bolivian experience (pp. 6382). Basingstoke: Palgrave Macmillan.

Zibechi, R. (2009). Los territorios como sustento del conflicto social. En F. Lozano y J. Ferrro, J. (Eds.), Las configuraciones de los territorios rurales en el siglo XXI (317333). Bogotá. Editorial Javeriana. 